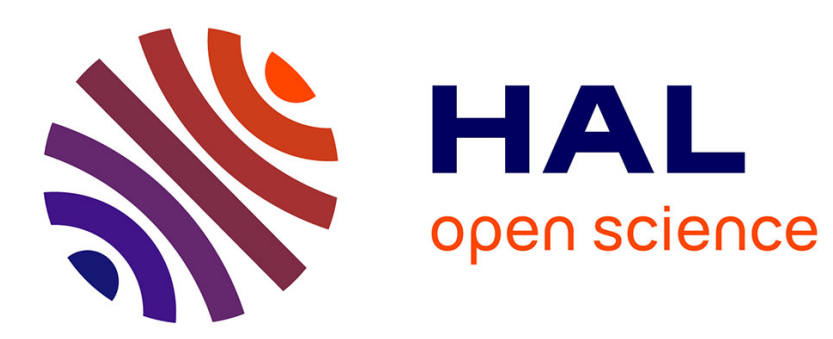

\title{
NMR STUDIES OF STRUCTURE AND DYNAMICS OF PHYSICALLY ADSORBED LAYERS ON UNIFORM SOLID SURFACES
}

B. Boddenberg, J. Moreno

\section{- To cite this version:}

B. Boddenberg, J. Moreno. NMR STUDIES OF STRUCTURE AND DYNAMICS OF PHYSICALLY ADSORBED LAYERS ON UNIFORM SOLID SURFACES. Journal de Physique Colloques, 1977, 38 (C4), pp.C4-52-C4-55. 10.1051/jphyscol:1977408 . jpa-00217124

HAL Id: jpa-00217124

https://hal.science/jpa-00217124

Submitted on 1 Jan 1977

HAL is a multi-disciplinary open access archive for the deposit and dissemination of scientific research documents, whether they are published or not. The documents may come from teaching and research institutions in France or abroad, or from public or private research centers.
L'archive ouverte pluridisciplinaire HAL, est destinée au dépôt et à la diffusion de documents scientifiques de niveau recherche, publiés ou non, émanant des établissements d'enseignement et de recherche français ou étrangers, des laboratoires publics ou privés. 


\title{
NMR STUDIES OF STRUCTURE AND DYNAMICS OF PHYSICALLY ADSORBED LAYERS ON UNIFORM SOLID SURFACES
}

\author{
B. BODDENBERG $(*)$ and J. A. MORENO (**) \\ Institut für Physikalische Chemie und Elektrochemie, \\ Technische Universität, Hannover, Germany.
}

\begin{abstract}
Résumé. - Les temps de relaxation spin réseau des protons de benzène adsorbé sur graphite microcristallin dans une monocouche ont été étudiées. Le modèle subséquent rend possible d'interpréter les résultats expérimentaux. Au-dessous de $-150^{\circ} \mathrm{C}$ les molécules sont orientées perpendiculairement à la surface et localisées sur des emplacements dans une structure hexagonale. Les molécules exécutent des sauts de réorientation autour de leurs axes de symétrie $\mathrm{C}_{2}$ à la fréquence $2,3 \times 10^{13} \exp (-1060 / T) \mathrm{s}^{-1}$.
\end{abstract}

\begin{abstract}
From proton spin lattice relaxation time measurements a model for the structure and microdynamics of a benzene monolayer on graphitized carbon black is developed. The essential results are that at temperatures below $-150^{\circ} \mathrm{C}$ benzene molecules are absorbed at definite sites of the graphite (0001) planes in ordered structure of hexagonal symmetry with the molecular planes oriented perpendicularly to the surface. The molecules perform reorientational jumps about diad molecular symmetry axes at a rate of $2.3 \times 10^{13} \exp (-1060 / T) \mathrm{s}^{-1}$.
\end{abstract}

1. Introduction. - In recent years the study of physisorbed layers on graphite has been promoted by the application of modern surface analysis techniques such as LEED and AES [1-3]. Whereas a rather clear-cut picture of the structure and phase transitions of layers of noble gases has been developed only little is known by such techniques about layers of physisorbed molecules [4]. On the other hand, an exceedingly large experimental material based on classical calorimetric and adsorption isotherm studies using graphitized carbon blacks as adsorbents may be found in the literature [5-7]. In addition, several theoretical papers have appeared which are concerned with the calculation of molecule-graphite surface potential energies $[7,8]$. However, the results of the above mentioned classical studies have up to date not found a satisfactory interpretation in terms of structural and dynamical models for the adsorption layers because of lack of knowledge on the nature of the adsorption forces, on the vibrational modes and frequencies as well as orientations and rotational motions of the adsorbed species, and on the translational/configurational state of the adsorbed layers.

$\left({ }^{*}\right)$ Permanent address : Lehrstuhl für Physikalische Chemie II, Universität Dortmund, Otto-Hahn-Strasse, 46 Dortmund 50 , Germany.

$\left({ }^{* *}\right)$ Permanent address: Departamento de Fisica, Facultad de Ciencias, Universidad Central de Venezuela, Caracas, Venezuela.
The present work reports on proton magnetic resonance relaxation studies of benzene adsorbed on graphitized carbon black (Graphon) surfaces [9]. Graphitized carbon blacks are adsorbents of reasonably high specific surface area $\left(5-80 \mathrm{~m}^{2} / \mathrm{g}\right)$ which possess nearly uniform surfaces since the particles expose predominantly the graphite lattice basal planes $[5,6]$. It has been claimed $[10]$ that the uniformity of the graphitized carbon black surfaces is exceeded only by that of exfoliated graphite.

NMR relaxation studies are well suited for the study of adsorption layers since under favourable conditions a wealth of information not only on structural properties but also on the microdynamical behaviour (rotational and translational motions) of molecules can be obtained. With respect to the inherent low sensitivity of NMR-methods no single crystal adsorption systems can be studied but the polycrystalline graphitized carbon blacks offer an ideally suited alternative.

2. Experimental. - The adsorbent used for the present investigation was the graphitized carbon black Graphon (Cabot Corp., Boston, Mass., USA) having a specific surface area of $80 \mathrm{~m}^{2} / \mathrm{g}$ as determined from low temperature nitrogen adsorption. Samples of about $0.5 \mathrm{~g}$ were prepared in NMR glass tubes which were attached to a high vacuum and gas handling system. The material was heated at $420^{\circ} \mathrm{C}$ for about 50 hours under high 
vacuum conditions $\left(10^{-6}\right.$ torr $)$. Known quantities of degassed and dried benzene $\mathrm{C}_{6} \mathrm{H}_{6}$ and $\mathrm{C}_{6} \mathrm{D}_{6}$ (Merck, Darmstadt, Germany) were transferred to the adsorbent to yield samples with surface coverages $\theta=1$ and 2 of various compositons with respect to the $\mathrm{C}_{6} \mathrm{H}_{6} / \mathrm{C}_{6} \mathrm{D}_{6}$ ratio. For use in the spectrometer the tubes were sealed off.

The proton spin-lattice relaxation times $T_{1}$ were measured at the resonance frequencies 16 and $60 \mathrm{MHz}$ with the aid of a pulsed NMR-spectrometer (B-KR $322 \mathrm{~s}$, Bruker-Physik, Karlsruhe, Germany) in conjunction with a signal averaging device (Model 1074, Nicolet-Instrum., Madison, Wisc., USA) and a transient recorder (B-C 104, Bruker-Physik) for signal to noise improvement and proper resolution of the solid-like signals at low temperatures. The saturation method was applied for the measurement of the $T_{1}$ relaxation times.

Temperature regulation and control in the range +20 to $-190^{\circ} \mathrm{C}$ was achieved by controlled flow of nitrogen gas evaporating from liquid nitrogen and thermocouple sensors, respectively. The sample temperatures were stabilized to $\pm 1^{\circ} \mathrm{C}$.

The experimental spin-lattice relaxation times $T_{1}(\alpha)$ of samples with given surface coverage but different fractions $\alpha$ of $\mathrm{C}_{6} \mathrm{H}_{6}$ molecules were used to separate the intermolecular dipolar relaxation rate $1 / T_{1, \text { inter }}$ from the contributions due to dipolar intramolecular and proton-electron interactions according to

$$
\frac{1}{T_{1}(\alpha)}=\frac{1}{T_{1, \text { eff }}}+\frac{23 \alpha+1}{24} \frac{1}{T_{1, \text { inter }}}
$$

with

$$
\frac{1}{T_{1, \text { eff }}}=\frac{1}{T_{1, \text { ntra }}}+\frac{1}{T_{1, \text { pe }}}
$$

3. Results and discussion. - Figure 1 shows the temperature dependence $\left(+20\right.$ to $\left.-190^{\circ} \mathrm{C}\right)$ of the proton spin-lattice relaxation times $T_{1, \text { eff }}$ and $T_{i, \text { inter }}$ of the one monolayer benzene graphitized carbon black system at $60 \mathrm{MHz}$ on a $\log T_{1}$ versus $1 / T$ scale. For sake of clarity of presentation the individual experimental points have been omitted. The limit of experimental error is $\pm 10 \%$. For the two monolayer sample the corresponding curves are similar to those shown in the figure, but an additional phase was observed which could be identified as solid crystalline benzene [11]. The number of molecules in this phase was found to be roughly equal to that being adsorbed in the monolayer.

The high temperature branches to the left of the dashed line shall not be discussed in the present context. It should be mentioned that the $T_{1 \text {,eff }}$ relaxation times in this temperature region are determined by proton-electron interactions [11]. This observation opens a new method of studying the electronic structure of the graphite surface via

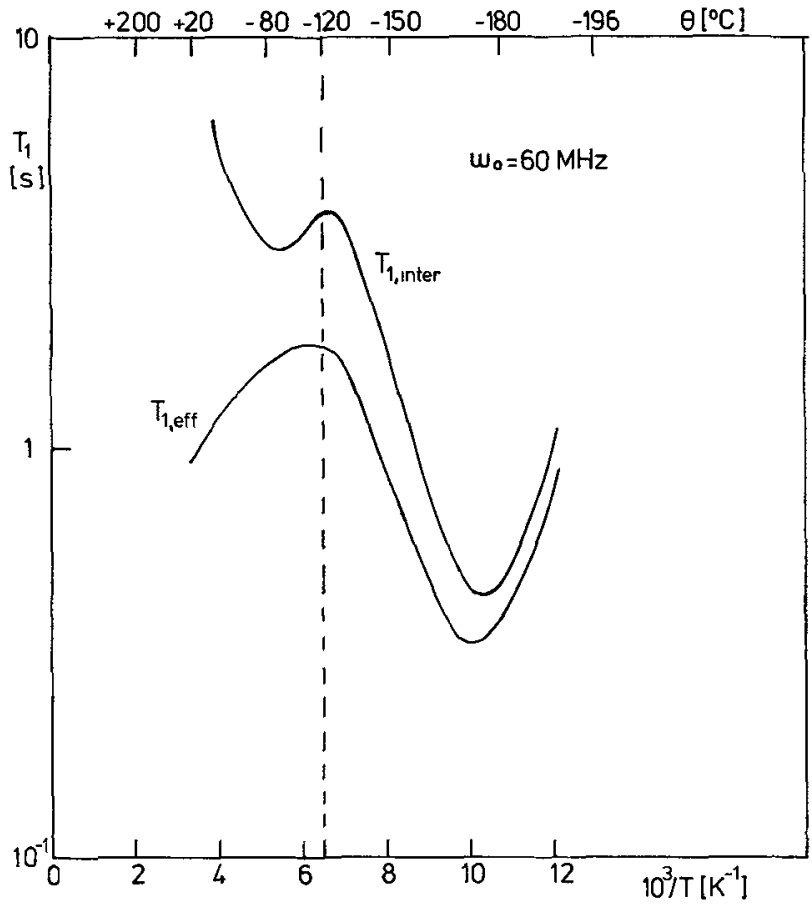

FIG. 1. $-60 \mathrm{MHz}$ effective $\left(T_{\mathrm{t}, \text { etf }}\right)$ and intermolecular $\left(T_{1 \text {, inter }}\right)$ spin-lattice relaxation times for a monolayer of benzene on graphitized carbon black.

proton relaxation time measurements of adsorbed species. The $T_{t, \text { inter }}$ data could be interpreted as due to translational motions of the adsorbed molecules [11].

The low temperature branches to the right of the dashed line are characterized by the appearance of well developed minima for both $T_{i, \text { eff }}$ and $T_{1, \text { inter }}$ at nearly the same temperature. In addition the same temperature dependence for both relaxation times is observed. It has been shown [11] that $\boldsymbol{T}_{\text {1,eff }}$ is dominated by intramolecular proton-proton interactions, the proton-electron contribution being negligible in the vicinity of the minimum.

The further discussion and interpretation of the experimental results in terms of structural and dynamical models of the adsorbed layer will be carried out separately for $T_{1, \text { intra }}$ and $T_{1, \text { inter }}$.

$3.1 T_{1, \text { intra }}$ - From the fact that a single well-developed minimum occurs in the temperature range being discussed it may be concluded that a certain rotational motion is performed by the spin-carrying molecules at a rate of $1 / \tau \approx \omega_{0}$ at the temperature of the minimum where $\omega_{0}$ is the NMR frequency. On the other hand, from relaxation time calculations [14] it may be shown that the value of $T_{1, \text { nura }}$ at the temperature of the minimum is determined by the type of the rotational motion, but does not depend on the specific temperature dependence of $\tau$ for the rotational models which will be discussed furtheron.

In the following we shall assume that each molecule performs the same type single-axis 
rotational motion where the axis of rotation is a symmetry axis of the molecule. Two types of rotational motions may be considered depending on whether the potential energy barriers separating accessible orientational positions of the molecule are small or large as compared to $k T$. In the former case Debye type diffusional rotational motion is indicated whereas in the latter case reorientational jump motions are considered to occur between a finite number of equilibrium orientational positions. For the jump type motions it is assumed that the jumps occur between the minima of an equal-wells potential, i.e. the equilibrium orientational positions of the molecule are transformed into each other by the operations of the cyclic $\mathrm{C}_{n}$ groups where $n$ may be either 2,3 , or 6 in view of the symmetry elements of the graphite (0001) plane as well as the benzene molecule.

In order to find out the rotational model which explains the experimental NMR data it is necessary to calculate from the appropriate relaxation time formula the value of $T_{1, \text { intra }}$ at the minimum for various models and to compare the results with the experimental ones. The only datum which enters into the theoretical calculations is the ortho-proton-proton distance in the benzene molecule $(2.495 \AA$ [12]) assuming the geometry of the benzene molecule to be retained on adsorption.

Table I lists the various rotational models that have been considered. In column 2 the symmetry axes of the benzene molecules about which the rotations occur are indicated. Here $2^{\prime}$ and $2^{\prime \prime}$ denote the two-fold axes which pass through the protons and the midpoints of the hexagon sides, respectively. Column 3 lists the groups $C_{n}$ the elements of which transform the orientational positions into each other in the case of jump motions. In column $4 \mathrm{D}$ and $\mathrm{j}$ denote the Debye rotational and the jump reorientational types of motions, respectively. For group orders $n>3$

\section{TABLE I}

Models for single-axis rotational motions of benzene molecules

$\begin{array}{cccc}\begin{array}{c}\text { Number } \\ \text { of model }\end{array} & \begin{array}{c}\text { Axis } \\ \text { of rotation }\end{array} & \begin{array}{c}\text { Symmetry } \\ \text { of motion }\end{array} & \begin{array}{c}\text { Type } \\ \text { of motion }\end{array} \\ \begin{array}{c}1 \\ 2\end{array} & - & - & - \\ 3 & 6 & - & \mathrm{D} \\ 4 & 6 & \mathrm{C}_{2} & \mathrm{j} \\ 5 & 6 & \mathrm{C}_{3} & \mathrm{j} \\ 6^{\prime}, 6^{\prime \prime} & 6 & \mathrm{C}_{6} & \mathrm{rj} \\ 7^{\prime}, 7^{\prime \prime} & 2^{\prime}, 2^{\prime \prime} & \mathrm{C}_{6} & \mathrm{sj} \\ 8^{\prime}, 8^{\prime \prime} & 2^{\prime}, 2^{\prime \prime} & - & \mathrm{D} \\ 9^{\prime}, 9^{\prime \prime} & 2^{\prime}, 2^{\prime \prime} & \mathrm{C}_{2} & \mathrm{j} \\ 10^{\prime}, 10^{\prime \prime} & 2^{\prime}, 2^{\prime \prime} & \mathrm{C}_{3} & \mathrm{j} \\ & & \mathrm{C}_{6} & \mathrm{rj} \\ \end{array}$

the r-jump ( $\mathrm{rj}$ ) and s-jump (sj) modes can be distinguished.

It turns out from the theoretical calculations that from all models listed in table I only models $10^{\prime}$ and $10^{\prime \prime}$ yield minimum values for $T_{1, \text { ntra }}$ which are in agreement with experiment in the range of experimental error (Tabl. II). The results indicate that the benzene molecules adsorbed on graphite (0001) planes reorient about either of the diad molecular symmetry axes in a sixfold equal-wells potential. The jumps occur to neighbouring orientational positions $\pm 60^{\circ}$ apart only.

\section{TABLE II}

Theoretical and experimental values of $T_{1, \mathrm{intr}}$ minima for rotational models $10^{\prime}, 10^{\prime \prime}$

$$
\begin{gathered}
\left(T_{1, \mathrm{nntra}}\right)_{\mathrm{Min}} \\
{[\mathrm{ms}]} \\
16 \mathrm{MHz} 60 \mathrm{MHz}
\end{gathered}
$$$$
\begin{array}{llll}
\text { Theory (models } 10^{\prime}, 10^{\prime \prime} \text { ) } & 82 & 306 \\
\text { Experiment } & \theta=1 & 83 & 330 \\
& \theta=2 & 78 & 310
\end{array}
$$

Several interesting conclusions may be drawn from this result.

(i) A site adsorption model must be valid since only this model is physically reasonable in view of the s-jump type of the reorientational motion.

(ii) The fact that the reorientational jumps occur about a twofold axis with six-fold symmetry can physically reasonably only explained if the molecules are standing up on the surface with the axis of reorientation being perpendicular to the surface.

(iii) With great probability the adsorption site is the center of a graphite hexagon. However, the possibility that a carbon atom is such a site cannot be discarded.

(iv) The notion of benzene molecules lying flat on the surface as has been assumed by almost all authors $[6,7,8]$ who have been concerned with the problem is not in accordance with the NMR results.

$3.2 T_{1, \text { mter }}$ - In general the intermolecular relaxation times are determined by the translational and/or rotational motions of the spin-carrying molecules. However, the previously mentioned experimental facts that the minimum of $T_{1, \text { nter }}$ appears in the vicinity of the $T_{1 \text {, intra minimum }}$ together with the conclusion of the preceding section that the site adsorption model is valid strongly suggest that only rotational motions determine $T_{1, \text { inter }}$. In addition, of course, $T_{1, \text { inter }}$ is strongly influenced by the arrangement of molecules on the graphite (0001) planes. Tentatively we assume that the molecules are arranged in an ordered structure being located on equivalent lattice positions of 
sixfold rotation site symmetries. In order to establish the correct lattice constant of the supposed two dimensional crystal as well as the appropriate reorientational model $\left(10^{\prime}\right.$ or $\left.10^{\prime \prime}, \mathrm{Tab} l . \mathrm{I}\right)$ it is again sufficient to calculate theoretical values for the minima of $T_{1, \text { inter }}$ and to compare the results with the experimentally determined data. The only new parameter which enters into the appropriate intermolecular relaxation time formulae [14] is the lattice constant of the graphite (0001) planes (2.456 $\AA[13]$ ). Of all the possibilities concerning arrangement of molecules and type of reorientational motion (alternative $10^{\prime} / 10^{\prime \prime}$ ) only one which is depicted in figure 2 is able to explain the NMR data and gives excellent agreement with experiment (Tabl. III).

\section{TABLE III}

Theoretical and experimental values for $T_{1, \text { inter }}$ minima

$$
\begin{gathered}
\left(T_{1, \text { inter }}\right)_{\mathrm{Mmn}} \\
{[\mathrm{ms}]} \\
16 \mathrm{MHz} 60 \mathrm{MHz}
\end{gathered}
$$

Theory (reorient. model 10", arrangement as in figure 2 )

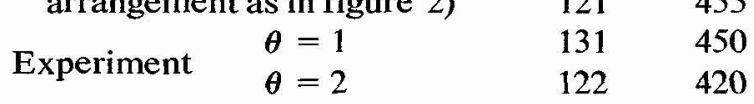

All other models that have been considered yield results which are at variance with the presently discussed one by at least $60 \%$ and are hence completely outside the range of experimental error.

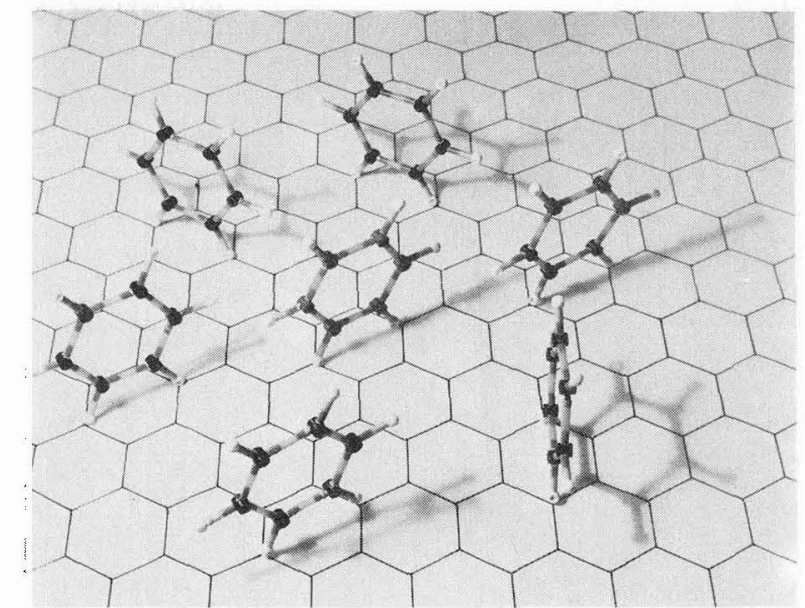

FIG. 2. - Snap-shot picture of a benzene monolayer on a graphite $(0001)$ plane showing orientation and arrangement of molecules.

3.3 JUMP TIMES. - The temperature dependences of both $T_{1, \text { intra }}$ and $T_{1, \text { inter }}$ are determined by the mean residence time $\tau$ of a molecule in a potential well. Assuming the jump process to be thermally activated with $\tau=\tau_{0} \exp (E / R T)$ both the $T_{1, \text { intra }}$ and $T_{1, \text { inter }}$ curves (Fig. 1) could be fitted with

$$
\tau=4.3 \times 10^{-14} \exp (1070 / T) \mathrm{s}
$$

Acknowledgments. - One of us (J.A.M.) thanks CONICIT, Venezuela, for a grant. Thanks are due to the Deutsche Forschungsgemeinschaft and the Fonds der Chemischen Industrie for financial support.

\section{References}

[1] Suzanne, J., Coulomb, J. P. and Bienfait, M., Surf. Sci. 40 (1973) 414.

[2] Suzanne, J., Coulomb, J. P. and Bienfait, M., Surf. Sci. 44 (1974) 141.

[3] Kramer, H. M. and Suzanne, J., Surf. Sci. 54 (1976) 659.

[4] LANDER, J. J. and Morrison, J., Surf. Sci. 6 (1967) 1.

[5] Ross, S. and OLIVIER, J. P., On Physical Adsorption (Interscience, New York), 1964

[6] Avgul, N. N. and Kiselev, A. V., Chem. Phys. Carbon 6 (1970) 1 , and references therein.

[7] Steele, W. A., The Interaction of Gases with Solid Surfaces (Pergamon, Oxford), 1974.
[8] Battezzati, L., Pisani, C. and Ricca, F., J. Chem. Soc., Faraday Trans. II 71 (1975) 1629.

[9] Boddenberg, B. and Moreno, J. A., Z. Naturforsch. 31a (1976) 854. (Short communication).

[10] Duval, X. and Thomy, A., C. R. 259 (1964) 4007.

[11] Moreno, J. A., Dissertation, Hannover, 1977.

[12] Andrew, E. R. and EAdes, R. G., Proc. R. Soc. A 218 (1953) 537.

[13] Wycoff, R. W. G., Crystal Structure, Vol. I, 2nd ed. (Interscience, New York).

[14] BoDdenberg, B, and Moreno, J.A., J. Magn., Resonance, in press.

\section{DISCUSSION}

F. A. PUtnam. - You have presented data at two coverages, $\theta=1$ and $\theta=2$. How did you determine the amount of benzene needed to attain these coverages?
B. BODDENBERG. - The amount needed for a monolayer coverage was determined from the $\mathrm{N}_{2}$-BET surface area of the sample and the area occupied by a benzene molecule. 